\title{
Myxosarcoma complicating a cystic hamartoma of the lung
}

\author{
C. STEPHANOPOULOS AND H. CATSARAS \\ From the Greek Seamen's Chest Hospital, Melissia, Athens
}

Primary myxomas and myxosarcomas of the lung are very rare. Stout studied in 1948 the records of Columbia University and the cases reported in the world literature and was able to collect 140 cases but there were no myxomas arising from the lung or pleura. Miller and Jackson (1954) reported a case of myxosarcoma of the lung and Barkley and Cardozo (1957) published another case of myxomatous tumour of the lingula extending to the pleura.

We have observed, and report herewith, a case of myxosarcoma arising from a congenital cyst of the lung and the histological findings confirm that this is a cystic hamartoma.

Cystic hamartomas are rare dysplastic tumours of the lung and they appear usually in premature infants. These tumours are also reported as adenomatous hyperplasiae (Ch"in and Tang, 1949). In newborn babies and infants they can be very large, occupying a whole lobe or lung, as distinct from the hamartomas of the adult which are usually smaller and circumscribed (Hochberg and Schacter, 1957). Cystic hamartomas are characterized by the overgrowth of bronchioles which causes lobar enlargement, while the development of the alveoli is suppressed except at the periphery (Campbell, 1957). These neoplasms grow into large cysts because of the development of a valvular mechanism, and it is then difficult to distinguish them radiologically from obstructive emphysematous cysts.

Malignant degeneration developing in congenital cysts of the lung, such as bronchogenic cysts, has been reported. But in all cases histological examination proved the presence of bronchial carcinoma (Womack and Graham, 1941; Moersch and Clagett, 1947; Korol, 1953; Murphy and Piver, 1951 ; Bass and Singer, 1951; Larkin and Phillips, 1955; West and Van Schoonhoven, 1957; Tala and Laustela, 1958). Myxomatous degeneration of a cyst of the lung has not been recorded in the literature.

\section{CASE REPORT}

A 2-year-old girl presented with anorexia, dry cough, dyspnoea, and some loss of weight following measles in April 1957.
The progressive dyspnoea was the reason for taking the first radiograph which showed a total left pneumothorax. Air, $200 \mathrm{ml}$., was removed from the pleural cavity at the hospital in Rodos. On 22 July 1957 she was admitted to the Greek Seamen's Chest Hospital.

The child when first seen was thin and ill. She was afebrile but dyspnoeic and slightly cyanosed. She had a dry cough. Clinically the left hemithorax was protruding; ther z was no air entry over the left side and on percussion there was marked hyper-resonance.

Chest radiographs showed a complete left-sided pneumothorax with mediastinal displacement to the right.

An attempt to help the lung to expand by simple removal of air was unsuccessful and continuous suction through a Morland needle was begun.

Within 48 hours the left lung expanded and the mediastinum became central, but a cyst with a fluid level was now apparent in the left lower lobe. In spite of this the general condition of the patient improved considerably. One month later she became dyspnoeic again and the chest radiograph showed that the cyst had enlarged enormously and was now pressing the left lung towards the apex, displacing the mediastinum to the right. Continuous suction for 48 hours through a Morland needle did not relieve the tension within the cyst and an exploratory thoracotomy was therefore performed on 17 September 1957. This revealed a large and very tense cyst arising from the axillary surface of the left lower lobe. The cyst was removed and the lung around the cyst leaked very little air. Th 2 upper and lower lobes expanded satisfactorily.

The post-operative course was uneventful and the patient left hospital on the tenth day after operation in a satisfactory condition with a fully expanding lung.

Histologically the wall of the cyst was thickened, forming multiple reduplications and papillary projections covered with a layer of high columnar ciliated epithelial cells, and consisted of a cellular connective tissue of embryonic type in which some small cystic formations were embedded. The surface of the cyst was covered with a layer of high columnar ciliated epithelial cells. The cystic formations embedded in this connective tissue were also composed of the same type of epithelial cells. The interstitial connective tissue consisted of small spindle-shaped or stellate cells containing small, round, or oval dark-stained nuclei and a homogeneous myxomatous ground substance. In some areas this substance was very abundant and the tissue showed a myxomatous appearance. 
These histological findings, particularly the embryonal type of interstitial connective tissu $;$ and the epithelial formation with the high columnar ciliated cells, suggest to us the embryonal nature of this neoplasm.

Four months later the patient was re-admitted to hospital. Her parents stated that for the first three months she had gained $3 \mathrm{~kg}$. in weight and was very active, but for the last two weeks she had had some cough, an evening rise in temperature, and a progressive degree of dyspnoea. Her general condition was obviously affected; there was definite dyspnoea, no air entry over the left lung, and the apex beat of the heart was over to the right of the midline. A chest radiograph showed a compact shadow over the left hemithorax and the mediastinum and heart were displaced to the right. Chest aspiration was repeatedly negative.

An exploratory thoracotomy was performed on 19 January 1958. The left hemithorax was full of neoplastic necrotic tissue. There was no clear plane of cleavage either to the mediastinum or to the diaphragm and a radical operation was not considered feasible. Some of the tumour was removed for histology and the chest was drained. The parents refused palliative radiotherapy and the child died 30 days later.

At necropsy the left lung was almost entirely destroyed and replaced by a soft myxomatous tumour. Many parts of this tumour were examined histologically and all showed the same structure. They consisted of a very cellular tissue similar to that observed in the first cyst but with an exaggerated cellular and nuclear pleomorphism and numerous mitoses. In some areas an abundant homogeneous myxomatous intercellular substance was present. No epithelial formation, as had been seen in the cyst wall and in other tissue, was found. The malignant nature of this tumour was evidenced by the numerous mitoses and the striking cellular and nuclear pleomorphism (myxosarcoma). The origin of this tumour from the embryonic connective tissue of the cyst is shown by the close similarity of both tissues.

\section{DISCUSSION}

It is generally accepted that myxomata are the result of degenerative changes of mesodermal tumours, such as fibromas, lipomas, chondromas, or other comparable tumours. The diagnosis therefore must be completed by histological evidence of the original growth.

Miller and Jackson (1954) accept the view that the myxosarcoma they observed probably arose from a hamartoma that had undergone myxomatous degeneration. Barkley and Cardozo (1957) believed in the possibility of a myxoma arising from a parent tumour, all evidence of which had been obliterated by myxomatous change.
The origin of the myxosarcoma in our case may be explained in the same way. Histological examination of the cyst gave evidence of a cystic hamartoma.

We consider the origin of the myxosarcoma from the embryonic connective tissue of the cystic hamartoma to be proved by the analogy of the morphological characteristics of these two neoplasms.

The cystic tumour was originally circumscribed and a valvular mechanism allowed ballooning of the cyst. After removal of the cyst, the lung expanded fully and there were at first no abnormal radiological signs. But one must accept the fact that parts of the tumour remained within the lung and caused the appearance of the large, rapidly developing myxosarcoma. It is not improbable that the spontaneous pneumothorax, the first appearance of the illness, was due to rupture of another cystic formation.

\section{SUMMARY}

A case of rapidly developing myxosarcoma of the lung in a 2-year-old girl is described. The condition appeared first as a left-sided pneumothorax; when the lung expanded a large tension cyst presented which had to be removed by thoracotomy. The histology of the removed cyst was compatible with cystic hamartoma and it is postulated that the myxosarcoma developed from remnants of this tumour. A second thoracotomy was performed four months later and a myxosarcoma was found to have infiltrated the whole lung, mediastinum, and diaphragm; its removal was not feasible. The child died 30 days after operation.

We wish to acknowledge with appreciation the pathological work done by Dr. N. Kandreviotis, Director of the Department of Pathology of Evangelismos Hospital.

\section{REFERENCES}

Barkley, H., and Cardozo, R. H. (1957). Thorax, 12, 264.

Bass, H. E., and Singer, E. (1951). Ann. intern. Med., 34, 498.

Campbell, J. A. (1957). In Bronchopulmonary Diseases, ed. E. A. Naclerio, p. 631. Hoeber, New York.

Ch'in, K. Y., and Tang, M. Y. (1949). Arch. Path., 48, 221.

Hochberg, L. A., and Schacter, B. (1957). In Bronchopulmonary Diseases, ed. E. A. Naclerio, p. 664. Hoeber, New York.

Korol, E. (1953). Dis Chest, 23, 403.

Larkin, J. C., and Phillips, S. (1955). Ibid., 27, 453.

Miller, A. A., and Jackson, F. B. (1954). J. Path. Bact., 68, 221.

Moersch, H. J., and Clagett, O. T. (1947). J. thorac. Surg., 16, 179.

Moersch, H. J., and Clagett, O. T. (1951). Dis. Chest, 19, 454.

Murphy, J. D., and Piver, J. D. (1951). Dis

Tala, P., and Laustela, E. (1958). Ann. Chir. Gynaec. Fenn., 47, 281.

West, J. P., and Van Schoonhoven, P. V. (1957). Surgery, 42, 1071.

Womack, N. A., and Graham, E. A. (1941). Amer. J. Path., 17, 645 . 